\title{
MENANAMKAN SIKAP MANDIRI DAN RASA TANGGUNG JAWAB MELALUI KEGIATAN FULL DAY SCHOOL DI TAMAN KANAK- KANAK
}

\author{
Ika Amalia ${ }^{1}$, Fiqih Rachmalia Astrini' \\ ikaamalia@gmail.com, Fiqihra.edu@gmail.com \\ Universitas Muhammadiyah Cirebon
}

\begin{abstract}
Kemandirian merupakan hal penting yang harus dimiliki oleh setiap individu untuk dapat menjalankan keseharian tanpa harus selalu bergantung pada orang lain, kemandirian juga menjadi penting bagi anak-anak untuk kesiapan di kehidupan yang akan datang. Sikap mandiri akan berdampingan dengan rasa tanggung jawab anak, hal ini dikarenakan ketika anak bersikap mandiri maka ia telah mengetahui konsekuensi apa yang akan ia terima atas sikap yang ia tunjukan dan ia siap dengan konsekuensi tersebut. Menanamkan sikap mandiri menjadi kewajiban semua pihak baik sekolah, guru serta orang tua. Adanya kegiatan full day school (FDS) yang kegiatannya bersifat pembiasaan dalam kecakapan hidup sehari-hari membuat anak menjadi terbiasa untuk bersikap mandiri dan bertanggungjawab. Penelitian ini dilakukan dengan menggunakan pendekatan kualitatif dengan metode penelitian fenomenologi untuk melihat secara menyeluruh dan mendalam mengenai menanamkan kemandirian dan rasa tanggung jawab melalui kegiatan full day school di Taman Kanak-kanak Cirebon. Responden dalam penelitian ini adalah guru sebagai pengajar FDS dan anak-anak yang mengikuti $F D S$. Alat pengumpulan data dalam penelitian ini yaitu menggunakan wawancara dan observasi. Kemudian data yang diperoleh dianalisis menggunakan teknik analisis data grounded theory. Hasil penelitian menunjukkan bahwa melalui kegiatan FDS anak dapat mengembangkan kemandirian dan rasa tanggungjawab karena kegiatan FDS banyak mengajarkan kepada anak tentang aktivitas keseharian melalui pembiasaan secara mandiri.
\end{abstract}

Keywords: full day school, pendidikan anak usia dini, anak usia dini, kemandirian, tanggungjawab

\footnotetext{
${ }^{1}$ Guru TK Negeri Pembina Cianjur

${ }^{2}$ Dosen tetap PG PAUD Universitas Muhammadiyah Cirebon
} 


\section{PENDAHULUAN}

Kemandirian merupakan modal bagi setiap individu dalam menjalankan hidup, kemandirian menurut Annesi (2005), Chen (2015), Lewis (2004) adalah sikap dan perilaku seseorang yang mencerminkan perbuatan yang cenderung individual, tanpa bantuan dan pertolongan dari orang lain. Kemandirian identik dengan kedewasaan, berbuat sesuatu tidak harus ditentukan atau diarahkan sepenuhnya oleh orang lain, seperti penjelasan Yusuf (2008) kemandirian merupakan karakteristik dari kepribadian yang sehat (healthy personality). Kemandirian individu tercermin dalam Cara berpikir dan bertindak, mampu mengambil keputusan, mengarahkan dan mengembangkan diri, serta menyesuaikan diri secara konstruktif dengan norma yang berlaku di lingkungannya. Adapun penjelasan Othman (2011), Lovell (2006), Lie (2004) kemandirian pada anak sangat diperlukan dalam rangka membekali mereka untuk menjalani kehidupan yang akan datang, sehingga anak akan mampu untuk menentukan pilihan dan bertanggung jawab atas risiko dan konsekuensi yang diakibatkan dari pilihannya tersebut.

$$
\text { Mendorong tumbuhnya }
$$

kemandirian anak usia dini, Musthafa (2008) menjelaskan bahwa orang tua dan guru perlu memberikan berbagai pilihan dan bila memungkinkan sekaligus memberikan gambaran kemungkinan konsekuensi yang menyertai pilihan yang diambilnya. Dalam lingkup taman kanak-kanak, aspirasi dan kemauan anak-anak pembelajar perlu didengar dan di akomodasi. Lebih lanjut Vandell
(2016) dalam konteks lingkungan keluarga di rumah, ini menuntut orang tua untuk lebih telaten dan sabar dengan Cara memberikan berbagai pilihan dan membicarakannya secara saksama dengan anak-anak setiap kali mereka dihadapkan pada pembuatan keputusan-keputusan penting. Semua ini diharapkan agar anak dapat membuat keputusan secara mandiri dan belajar dari konsekuensi yang ditimbulkan keputusan yang diambilnya.

Melalui kegiatan full day school (FDS) di taman kanak-kanak dapat memberikan kontribusi yang cukup baik dalam memberikan stimulus untuk mengembangkan kemandirian anak, kemandirian tidak terlepas dari tanggung jawab seperti yang dijelaskan sebelumnya oleh Othman (2011), Lovell (2006), Lie (2004) bahwa sikap mandiri anak baik dalam mengambil keputusan juga melakukan sesuatu atas dasar keinginan sendiri dan kemampuannya sendiri maka muncul juga rasa tanggung jawab atas konsekuensi yang mungkin terjadi atas keputusan dan perilaku yang mereka lakukan. Kegiatan FDS yang bersifat pembiasaan dan banyak dilakukan aktivitas yang sifatnya mandiri maka membantu anak dalam mengembangkan kemandirian mereka.

\section{METODOLOGI PENELITIAN}

Pendekatan dalam penelitian ini adalah pendekatan kualitatif dengan menggunakan metode penelitian fenomenologi, peneliti memilih metode fenomenologi dalam penelitian ini karena ingin melihat secara mendalam dan menyeluruh 
menurut Bungin (2010), Creswell (2013) khususnya dalam penelitian ini yaitu perihal menanamkan sikap mandiri dan rasa tanggung jawab melalui kegiatan FDS mulai dari perencanaan, implementasi hingga hasil yang diperoleh dari kegiatan FDS itu sendiri. Responden dalam penelitian ini yaitu tiga guru dan anak-anak yang mengikuti $F D S$. Sedangkan teknik analisis data menggunakan teknik analisis grounded theory. Adapun alat yang digunakan dalam pengumpulan data dalam penelitian ini menggunakan observasi dan wawancara tidak terstruktur, sebagai key instrumen dalam penelitian ini peneliti mengembangkan pertanyaan yang bersifat terbuka untuk dapat menggali informasi sesuai kebutuhan penelitian.

\section{HASIL DAN PEMBAHASAN}

Hasil penelitian menunjukkan bahwa melalui kegiatan $F D S$ anak dapat mengembangkan kemandirian dan rasa tanggung jawab, hal itu dibuktikan melalui aktivitas keseharian yang membiasakan diri anak untuk bersikap mandiri. Seperti saat kegiatan makan, anak makan sendiri tanpa disuapi dengan guru, jika saat makan ada remah-remah makanan yang tumpah maka anak secara otomatis membersihkan remah-remah makanan tersebut. Kemandirian yang berlangsung saat kegiatan makan itu membuat anak juga memiliki rasa tanggung jawab atas kebersihan dan kerapuhan lingkungan tempat anak sedang makan. Begitu juga saat kegiatan tidur siang, dimana anak yang akan tidur siang mempersiapkan kasur dan peralatan tidurnya kemudian jika bangun di sore hari, anak juga bertanggung jawab atas peralatan tidur yang telah mereka pakai.

Keterkaitan kemandirian anak dengan tanggung jawab memang tidak dapat dipisahkan, karena munculnya kemandirian itu sendiri atas dasar kesiapan anak dalam menerima risiko yang mungkin akan muncul dari keputusan yang ia ambil atau perilaku yang dia lakukan. Oleh karenanya Kaplan (2015) menjelaskan tentang adanya keinginan dan kesiapan dari dalam diri individu ketika akan bersikap mandiri, intinya diungkapkan juga oleh Palmer (2012), Curran (2013), Zheng (2015) bahwa dirinya ingin melakukan itu dengan kemampuan sendiri dan siap dengan apapun yang akan terjadi apabila individu tersebut mau melakukannya sendiri. Adapun yang diungkapkan oleh Shancez (2014) yang memandang kemandirian bagi anak usia dini sangatlah penting karena kemandirian akan selalu ada dalam kegiatan sehari-hari anak untuk saat ini, juga untuk kehidupan anak di masa yang akan datang. Lebih lanjut Rodreguez (2013), Rutten (2013) memaparkan akan menyesuaikan dengan tahapan perkembangan mereka sendiri, dengan kesesuaian tahapan perkembangannya maka anak akan dapat bertanggung jawab atas sikap mandiri yang ia lakukan.

Kemandirian pada anak usia dini tidak muncul begitu saja, tentu ada faktor yang mendukung atas munculnya sikap mandiri pada anak seperti yang dikatakan oleh Miler (2010), dan Palmer (2012) bahwa anak yang diberikan kebebasan baik dalam memiliki sesuatu ataupun dalam bertindak memiliki 
kecenderungan untuk bersikap bersikap mandiri yang juga mandiri. Faktor lain yang ditentukan oleh bagaimana menentukan kemandirian anak lingkungan, pola asuh dan dijelaskan oleh (Bruce 2016, Fenner pembelajaran di sekolah memberikan 2016, Kline 2007, Sanli 2013, Yiwu kesempatan juga menuntut mereka 2012) bahwa adanya motivasi untuk bersikap mandiri. intrinsik dari anak untuk mau

\section{REFERENSI}

Bungin, Burhan. (2010). Metode Penelitian Sosial-Format Kualitatif. Surabaya: Airlangga University Press.

Baradja, A. (2005). Psikologi perkembangan: Tahapan-tahapan dan aspekaspeknya. Jakarta: Studia Press.

Creswell W. John. (2013). Research Design Pendekatan Kualitatif, Kuantitatif, dan Mixed. Yogyakarta: Pustaka Pelajar.

Annesi. (2005). Self-determination of young children with intellectual disability: understanding parents' perspectives. British Journal of Special Education. 40(4), 175-181.

Chen, Weiyun. 2015. Elementary School Students' Self-Determination in Physical Education and Attitudes Toward Physical Activity. Journal of Teaching in Physical Education. 34(4), 189 -209:

Lewis, A. Barbara. (2004). Character Building. Batam: Karisma Publish Group

Curran, Thomas. 2013. A Conditional Process Model of Children's Behavioural Engagement and Behavioural Disaffection Sport Based on Self-Determination Theory. Journal of Sport \& Exercise Psychology. 35, 30-43.

Fenner, Ashley. 2016. Exploration of the Mechanisms of Change in Constructs From Self-Determination Theory and Quality of Life During a Multidisciplinary Family-Based Intervention Overweight Adolescents. Journal of Sport \& Exercise Psychology. 38(6), 59-68.

Kaplan, Haya. 2015. Autonomous Motivation and Pro-Environmental Behaviours Among Bedouin Students in Israel: A SelfDetermination Theory Perspective. Australian Journal of Environmental Education. 31(2), 223-247.

Rutten, Cindy. 2015. Changes in Children's Autonomous Motivation Toward Physical Education During Transition From Elementary to Secondary School: : of Teaching in Physical Education. 34(5), 442-460.

Sanchez, David. 2014. Physical Education Lessons and Physical Activity Intentions Within Spanish Secondary Schools: A SelfDetermination Perspective. Journal of Teaching in Physical Education. 33(6), 232-249. 
Kline. (2007).Understanding self-controlled motor learning protocols through the self-determination theory. Frontiers in psychology. $3(1), 1-17$.

Shen, April. 2009. Self-Esteem of Young Adults Experiencing Interparental Violence and Child Physical Maltreatment: Parental and Peer Relationships as Mediators. Journal of Interpersonal Violence. 24(5), 770-794.

Teixeira, Pedro. 2012. Exercise, physical activity, and self-determination theory: A systematic review. International Journal of Behavioural Nutrition and Physical Activity. 78(9), 1-30.

Yiwu, Hsiang. 2012. Self-Determination of Young Children With Special Needs From Culturally and Linguistically Diverse Backgrounds. Preventing School Failure, 56(3), 149-156

Zheng, Yuzhu. 2015. Foundations for Self-Determination Perceived and Promoted by Families of Young Children with Disabilities in China. Education and Training in Autism and Developmental Disabilities. 50(1), 109-122.

Leng. (2014). The Relationship between Self-Concept, Intrinsic Motivation, Self-Determination and Academic Achievement among Chinese Primary School Students. Journal of Interpersonal Violence. 21(3), 362-400.

Palmer. (2012). Foundations for Self-Determination in Early Childhood: An Inclusive Model for Children With Disabilities. Journal of Teaching in Physical Education. 12(6), 88-164.

Rodreguez. (2013). How Many Times Do We Stop Being Children? An Analysis on the Social Representation of Children's Autonomy. Journal of Teaching in Physical Education. 12(1), 51-77.

Williams. (2014). Parent Emotion Socialization Practices and Child Selfregulation as Predictors of Child Anxiety: The Mediating Role of Cardiac Variability. Child Psychiatry Hum Dev. 46(3), 512-522.

Othman, Nooraini. Leng, Bee. (2011). Relationship Between Self Concept, Intrinsic Motivation, Self Determination, and Academic Achievement Among Chinese Students. International Journal of Psychology Studies. (3) 1. 13-22.

Lie A. \& Prasasti S. (2004). 101 Cara Membina Kemandirian dan Tanggung Jawab Anak. Jakarta: Elex Media Komputindo. 
JURNAL JENDELA BUNDA

Vol 6 No 1 Maret-Agustus 2018 